\title{
Can local staff reliably assess their own programs? A confirmatory test-retest study of Lot Quality Assurance Sampling data collectors in Uganda
}

Colin A. Beckworth ${ }^{1 *}$, Robert Anguyo ${ }^{2}$, Francis Cranmer Kyakulaga ${ }^{3}$, Stephen K. Lwanga ${ }^{4}$ and Joseph J. Valadez ${ }^{1}$

\begin{abstract}
Background: Data collection techniques that routinely provide health system information at the local level are in demand and needed. LQAS is intended for use by local health teams to collect data at the district and sub-district levels. Our question is whether local health staff produce biased results as they are responsible for implementing the programs they also assess.
\end{abstract}

Methods: This test-retest study replicates on a larger scale an earlier LQAS reliability assessment in Uganda. We conducted in two districts an LQAS survey using 15 local health staff as data collectors. A week later, the data collectors swapped districts, where they acted as disinterested non-local data collectors, repeating the LQAS survey with the same respondents. We analysed the resulting two data sets for agreement using Cohens' Kappa.

Results: The average Kappa score for the knowledge indicators was $\mathrm{k}=0.43(\mathrm{SD}=0.16)$ and for practice indicators $k=0.63(S D=0.17)$. These scores show moderate agreement for knowledge indicators and substantial agreement for practice indicators. Analyses confirm that respondents were more knowledgeable on retest; no evidence of bias was found for practice indicators.

Conclusion: The findings of this study are remarkably similar to those produced in the first reliability study. There is no evidence that using local healthcare staff to collect LQAS data biases data collection in an LQAS study. The bias observed in the knowledge indicators was most likely due to a 'practice effect', whereby respondents increased their knowledge as a result of completing the first survey; no corresponding effect was seen in the practice indicators.

Keywords: LQAS, Lot Quality Assurance Sampling, Test retest, Cohen's kappa, Bias

Abbreviations: Cl, Confidence interval; HIV, Human immunodeficiency virus; HMIS, Health management information system; LQAS, Lot quality assurance sampling; NGO, Non-governmental organisation; SA, Supervision area; SD, Standard deviation; STI, Sexually transmitted infection; TB, Tuberculosis; UN, United nations; UNICEF, United nations children's fund; WHO, World health organisation

\footnotetext{
*Correspondence: cbeckworth74@gmail.com

'Liverpool School of Tropical Medicine, Pembroke Place, Liverpool L3 5QA,

United Kingdom

Full list of author information is available at the end of the article
} 


\section{Background}

Health surveys are, arguably, the "the primary method for estimating population-level intervention coverage in lowand middle-income countries" [1]. Despite progress made since the World Health Organisation's (WHO) Advisory Panel on Health Statistics called for more and better health statistics [2], there are still challenges to overcome. Routine health management information systems (HMIS) can provide valuable health service demand-side information, but being a convenience sample is inadequate for measuring coverage and supporting related programmatic decisionmaking [3]. Whilst macro-level surveys provide detailed high quality information, they do not provide the local-level information that is necessary for local program management. More research about data collection techniques which can routinely provide information at the local level is in demand and needed [1]. Lot Quality Assurance Sampling (LQAS) may contribute to satisfying this need [4].

LQAS is a classification method derived from the original work of Dodge and Romig [5], which together with that of Shewhart [6], grew to become Statistical Quality Control. During the 1980's it made its transition into the health sciences, gaining wide appeal [7]. During the 1990s WHO favourably reviewed the methodology as providing regular coverage data at the local level [8].

LQAS has two stages, but first requires dividing a program area (such as a district) into smaller sub-areas (or sub-districts) called Supervision Areas (SA). In the first stage a random sample is collected within each SA and used to classify the SA as acceptably or unacceptably performing according to a predetermined threshold [9]. In the second stage the data from SA are aggregated to measure the prevalence of program areas as a whole. This methodology has been extensively used by UN agencies, Ministries of Health and NGOs to periodically collect data to manage health programs using local health staff to collect data [8].

However, as LQAS is intended for use by local program managers, the question must be examined as to whether local health staff produce biased results as they are responsible for implementing the programs they also assess. This question is not trivial as bias is described as "the greatest threat to reliability and validity" of collected data [10].

An initial, albeit small scale, study assessing whether local data collectors are a source of bias in LQAS survey [11], found no evidence to support the hypothesis that they bias the data they collect. However, that study was restricted to one district, and the second set of disinterested data collectors came from the same district; also the sample size was small consisting of 76 participants. This current study is designed as a larger confirmatory test-retest study to measure inter-observer reliability of LQAS data collection. The study was located in two districts in Uganda.

\section{Methods}

We used a test-retest methodology to compare the interobserver reliability between two groups of data collectors when carrying out an LQAS survey. Inter-observer reliability is the degree of agreement between two different data collectors when making observations of the same phenomenon [12]. Test-retest measures the inter-observer reliability of the data collected by two independent sets of data collectors [13]. Provided the phenomenon under examination has not changed, the two sets of observations should be the same; the greater the agreement between the two observations, the greater the inter-observer reliability.

In our study, the first group of data collectors was an 'interested' group responsible for managing the service provision being assessed. The second group was a 'disinterested' group who were not responsible for service provision and/or management in the same area. We introduced no other change. We used this test-retest study to examine the agreement of the information provided by data collectors with a vested interest in the results (the interested data collectors) as opposed to those without a vested interest (the disinterested data collectors) and whether the former collect biased data.

The study site was two districts in Uganda $200 \mathrm{~km}$ apart, Buikwe and Bukomansimbi. These two districts had previously carried out several rounds of LQAS using 15 data collectors in each district. Each district was subdivided into five SAs. For the 'test' phase of the research, the data collection teams administered a questionnaire in their home districts using the standard method [14]. Since the teams were in their home districts where they were responsible for providing services, we labelled them as 'interested' data collectors. One week later, the 15 data collectors from Bukomansimbi moved to Buikwe, and the 15 data collectors from Buikwe moved to Bukomansimbi. The teams then carried out the 'Retest', using the same questionnaire with the same respondents as previously surveyed. However, since the teams were no longer in their home districts and had no responsibility for service provision, we labelled them as 'disinterested' data collectors. Nineteen respondents were selected randomly from each SA for the LQAS classification. With $n=19$ alpha and beta errors do not exceed 0.10 for high or very low performing SA [14]. The total district sample is $n=95$ $(5 \times 19)$. Therefore, $n=190$ respondents for the full study. We employed probability proportional to size sampling to select 19 interview locations in each SA and segmentation sampling to select respondent households. The respondents were confirmed as being the same respondent by checking their name; village; whether they had given information for a survey a week previously and where possible by their mobile phone number.

The data collection teams were selected by the senior district health managers, who were all experienced with using 
LQAS data. We requested the district health managers to select the data collectors who had collected data during previous rounds of LQAS; the teams comprised 21 clinical staff and nine non-clinical support staff. Twenty-five of the staff were full time employees of the districts; the other five were periodically employed by the health district when needed. All of the data collectors attended a four-day LQAS data collector training course from 9th to the 13th of September 2013. The data collectors were not informed of the true aim of the study so as not to prejudice the data collection. Rather they were told that the study was being carried out to examine operational issues associated with implementing LQAS in the districts. After the completion of the study, the teams were informed of the true reason for the study and results were fed back to the districts-which is the intention of LQAS assessments.

The questionnaire was adapted from a pre-tested LQAS questionnaire for mothers of children $0-11$ months old used previously in multiple districts throughout Uganda to explore knowledge and practices around malaria, TB, HIV and other sexually transmitted infections (STI). The questionnaire was adapted so that questions for which the answer could change between the test and the retest were excluded. The questionnaire was the same one as used in a previous smaller LQAS reliability study [11]. Therefore, the results for this study are directly comparable to the previous LQAS reliability study. The resulting questionnaire produced 23 indicators pertaining to the respondents' knowledge and 14 indicators pertaining to practice. The data were double entered using EpiInfo 7 and analysed using SPSS v21.

The test and retest data were analysed for agreement using Cohen's Kappa. This test measures agreement between two scores and is widely used in test-retest studies [15]. We chose Cohen's Kappa because since it is an appropriate statistic to measure inter-rater reliability with nominal data [16], and other authors have used Kappa for this type of analysis $[17,18]$. The Kappa score ranges between 0 (no agreement) and 1 (complete agreement) [19], the interpretation for which we include in Table 1 . However, we noted that because of the base rate problem, Kappa can be unstable at very high or very low prevalence [20]. We

Table 1 Standard Categories to Interpret Kappa values (Landis \& Koch 1977)

\begin{tabular}{ll}
\hline Kappa Value $\underline{(\mathrm{k})}$ & Strength of Agreement \\
\hline$<0.00$ & Poor \\
$0.00-0.20$ & Slight \\
$0.21-0.40$ & Fair \\
$0.41-0.60$ & Moderate \\
$0.61-0.80$ & Substantial \\
$0.81-1.00$ & Almost Perfect \\
\hline
\end{tabular}

therefore excluded from our analysis any indicator where the "a" or "d" cells include in the cross tabulation were $<5$.

Ethical approval for this research was granted by Makerere School of Public Health, and approval was given by the Uganda National Council of Science and Technology. Written informed consent was obtained for all participants in the study, and the consent form was approved by the ethics committee.

\section{Results}

Table 2 shows the coverage estimates for the practice indicators on the test and retest for the two districts. Table 3 does the same for knowledge indicators. The results from the test and the retest were then analysed using a paired $t$-test; the resulting $p$ values are displayed in the column following the test and retest coverage estimates. The $p$ values range from $<0.001$ to 1 for knowledge and 0.083 to 1 for the practice indicators. Of the 34 results analysed for the knowledge indicators, only six had a $p$ value of $\leq 0.05$. Of these six, only one was higher on the test, when the interested data collectors were collecting the data. None of the 26 results analysed for the practice indicators had a $p$ value $\leq 0.05$.

Tables 4 and 5 show the Kappa scores for the knowledge and practices indicators respectively. The average Kappa score for the knowledge indicators was $\mathrm{k}=0.43$ $(\mathrm{SD}=0.16)$ and for practice indicators $\mathrm{k}=0.63(\mathrm{SD}=0.17)$, (Tables 4\&5). These scores show moderate agreement for knowledge indicators and substantial agreement for practice indicators.

Further analyses explored the direction of the discordant results to assess bias in health worker interviews. A respondent who answers correctly to a knowledge question (such as knowing the ways HIV can be transmitted to an infant) or who responds that they practice a desirable health behaviour (such as a mother going for four or more antenatal care visits) is scored as giving a 'positive' response. Positive responses show that health services are performing well in a particular area. Bias can be defined as systematic error, as compared with random error [21]. Our survey examined knowledge and practices of Ugandans concerning malaria, TB and HIV/STI. If local health workers collected biased data then their responses should be consistently and significantly more positive than those of the disinterested data collectors.

We categorized the indicators as either knowledge or practice. Knowledge indicators measured whether a respondent could correctly state key health messages; practice indicators measured whether respondents had practiced key health behaviours. We separated the indicators so that we could examine the results for bias by indicator type.

On average, the additional number of positive responses on the retest was 6.7 for knowledge indicators (95\% CI $=3.0$ to 10.4 ) and -0.2 for the practice ones 
Table 2 Coverage Estimates for Practice Indicators

\begin{tabular}{|c|c|c|c|c|c|c|c|}
\hline & & Bukoma & & & Buikwe & & \\
\hline & & Test & Retest & $p$ & Test & Retest & $p$ \\
\hline 1 & Could show an ANC card & $58.9 \%$ & $62.1 \%$ & 0.32 & $73.7 \%$ & $69.5 \%$ & 0.103 \\
\hline 2 & Gave birth in health facility & $74.7 \%$ & $76.8 \%$ & 0.158 & $74.7 \%$ & $80.0 \%$ & 0.132 \\
\hline 3 & Gave birth with a skilled birth attendant & $71.6 \%$ & $69.5 \%$ & 0.566 & $73.7 \%$ & $77.9 \%$ & 0.25 \\
\hline 4 & Has ever used a condom & $57.9 \%$ & $53.7 \%$ & 0.287 & $71.6 \%$ & $71.6 \%$ & 1 \\
\hline 5 & Owns a LLIN & $85.3 \%$ & $84.2 \%$ & 0.765 & $82.1 \%$ & $76.8 \%$ & 0.096 \\
\hline 6 & Received IPT whilst pregnant & $46.3 \%$ & $54.7 \%$ & 0.45 & $58.9 \%$ & $54.7 \%$ & 0.348 \\
\hline 7 & Received PMTCT counselling & $76.8 \%$ & $77.9 \%$ & 0.798 & $83.2 \%$ & $87.4 \%$ & 0.25 \\
\hline 8 & Received result & $81.1 \%$ & $80.0 \%$ & 0.741 & $85.3 \%$ & $86.3 \%$ & 0.765 \\
\hline 9 & Slept under a mosquito net whilst pregnant & $83.2 \%$ & $89.5 \%$ & 0.083 & $82.1 \%$ & $83.2 \%$ & 0.708 \\
\hline 10 & Slept under mosquito net every night whilst pregnant & $69.5 \%$ & $72.6 \%$ & 0.551 & $77.9 \%$ & $75.8 \%$ & 0.566 \\
\hline 11 & Took an HIV test & $82.1 \%$ & $83.2 \%$ & 0.741 & $90.5 \%$ & $90.5 \%$ & 1 \\
\hline 12 & Went for 4 ANC visits & $44.2 \%$ & $44.2 \%$ & 1 & $42.1 \%$ & $35.8 \%$ & 0.083 \\
\hline 13 & Was counselled to take an HIV test & $86.3 \%$ & $85.3 \%$ & 0.783 & $93.7 \%$ & $92.6 \%$ & 0.708 \\
\hline
\end{tabular}

(95\% CI $=-2.9$ to 2.5 ) (Figs. 1 and 2). These results indicate that respondents were significantly more knowledgeable during the retest with the disinterested data collectors; 13 of the 17 knowledge indicators show positive values during the retest (Fig. 1) with only one negative value. The practice indicators show no difference between the test and retest (Fig. 2). Six values are positive (above the $x$ axis) and six negative (below the $x$ axis). These data reveal no significant or consistent directional difference for the practice indicators and therefore, no bias. Data for the test,

Table 3 Coverage Estimates for Knowledge Indicators

\begin{tabular}{|c|c|c|c|c|c|c|c|}
\hline & & \multicolumn{3}{|c|}{ Bukomansimbi } & \multicolumn{3}{|l|}{ Buikwe } \\
\hline & & Test & Retest & $p$ & Test & Retest & $p$ \\
\hline 1 & $\begin{array}{l}\text { Knows at least one way that the risk of mother to child } \\
\text { transmission can be reduced }\end{array}$ & $88.4 \%$ & $89.5 \%$ & 0.708 & $90.5 \%$ & $93.7 \%$ & 0.32 \\
\hline 2 & Knows at least two actions to take if they have an STI & $33.7 \%$ & $41.1 \%$ & 0.288 & $34.7 \%$ & $37.9 \%$ & 0.615 \\
\hline 3 & Knows at least two signs of STI in females & $77.9 \%$ & $82.1 \%$ & 0.158 & $81.1 \%$ & $91.6 \%$ & 0.001 \\
\hline 4 & Knows at least two signs of STI in males & $45.3 \%$ & $54.7 \%$ & 0.038 & $58.9 \%$ & $65.3 \%$ & 0.158 \\
\hline 5 & Knows of at least one STI other than HIV & $86.3 \%$ & $89.5 \%$ & 0.259 & $94.7 \%$ & $96.8 \%$ & 0.158 \\
\hline 6 & $\begin{array}{l}\text { Knows that HIV can be transmitted to an infant during } \\
\text { breastfeeding }\end{array}$ & $57.9 \%$ & $62.1 \%$ & 0.397 & $65.3 \%$ & $70.5 \%$ & 0.3 \\
\hline 7 & $\begin{array}{l}\text { Knows that HIV can be transmitted to an infant during } \\
\text { delivery }\end{array}$ & $73.7 \%$ & $68.4 \%$ & 0.253 & $69.5 \%$ & $74.7 \%$ & 0.32 \\
\hline 8 & $\begin{array}{l}\text { Knows that HIV can be transmitted to an infant during } \\
\text { pregnancy }\end{array}$ & $24.2 \%$ & $28.4 \%$ & 0.453 & $36.8 \%$ & $18.9 \%$ & 0.002 \\
\hline 9 & $\begin{array}{l}\text { Knows that the risk of mother to child transmission can } \\
\text { be reduced }\end{array}$ & $90.5 \%$ & $91.6 \%$ & 0.657 & $91.6 \%$ & $95.8 \%$ & 0.208 \\
\hline 10 & Knows the three strategies to prevent HIV infection & $5.3 \%$ & $7.4 \%$ & 0.482 & $7.4 \%$ & $12.6 \%$ & 0.167 \\
\hline 11 & Knows where to get treatment for STI & $77.9 \%$ & $85.3 \%$ & 0.07 & $86.3 \%$ & $95.8 \%$ & 0.006 \\
\hline 12 & Knows whether HIV is transmitted via Mosquitoes & $63.2 \%$ & $68.4 \%$ & 0.198 & $61.1 \%$ & $63.2 \%$ & 0.62 \\
\hline 13 & $\begin{array}{l}\text { Knows whether HIV is transmitted via sharing food with } \\
\text { infected person }\end{array}$ & $82.1 \%$ & $88.4 \%$ & 0.109 & $76.8 \%$ & $84.2 \%$ & 0.109 \\
\hline 14 & Knows whether HIV is transmitted via sharing toilets & $81.1 \%$ & $81.1 \%$ & 1 & $74.7 \%$ & $83.2 \%$ & 0.02 \\
\hline 15 & Knows whether HIV is transmitted via sharing utensils & $67.4 \%$ & $88.4 \%$ & 0 & $77.9 \%$ & $74.7 \%$ & 0.494 \\
\hline 16 & Knows whether HIV is transmitted via touching infected person & $89.5 \%$ & $91.6 \%$ & 0.566 & $85.3 \%$ & $91.6 \%$ & 0.096 \\
\hline 17 & Knows whether HIV is transmitted via witchcraft & $85.3 \%$ & $86.3 \%$ & 0.62 & $88.4 \%$ & $91.6 \%$ & 0.47 \\
\hline
\end{tabular}


Table 4 Kappa Scores for Knowledge Indicators

\begin{tabular}{|c|c|c|c|c|c|c|c|}
\hline \multirow[t]{2}{*}{ No. } & \multirow[t]{2}{*}{ Indicator } & \multicolumn{2}{|c|}{ Interviewer Agreement } & \multicolumn{2}{|c|}{ Disagreement } & \multirow[t]{2}{*}{ Kappa } & \multirow{2}{*}{$\begin{array}{l}\text { Strength of } \\
\text { Agreement }\end{array}$} \\
\hline & & yes & no & yes \& no & no \& yes & & \\
\hline 1 & Know of at least one STI other than HIV & 11 & 170 & 7 & 2 & 0.69 & Substantial \\
\hline 2 & Know whether HIV is transmitted via Mosquitoes & 53 & 106 & 19 & 12 & 0.65 & Substantial \\
\hline 3 & Know whether HIV is transmitted via sharing toilets & 27 & 141 & 15 & 7 & 0.64 & Substantial \\
\hline 4 & Know at least two signs of STI in females & 37 & 116 & 29 & 8 & 0.54 & Moderate \\
\hline 5 & Know at least two signs of STI in males & 105 & 45 & 28 & 12 & 0.54 & Moderate \\
\hline 6 & $\begin{array}{l}\text { Know at least one way that the risk of mother to child } \\
\text { transmission can be reduced }\end{array}$ & 10 & 164 & 10 & 6 & 0.51 & Moderate \\
\hline 7 & $\begin{array}{l}\text { Know that HIV can be transmitted to an infant during } \\
\text { breastfeeding }\end{array}$ & 46 & 99 & 27 & 18 & 0.49 & Moderate \\
\hline 8 & $\begin{array}{l}\text { Knows the risk of mother to child transmission can be } \\
\text { reduced }\end{array}$ & 7 & 168 & 10 & 5 & 0.44 & Moderate \\
\hline 9 & Knows HIV can be transmitted to an infant during delivery & 32 & 114 & 22 & 22 & 0.43 & Moderate \\
\hline 10 & Know where to get treatment for STI & 13 & 151 & 21 & 5 & 0.43 & Moderate \\
\hline 11 & Know whether HIV is transmitted via sharing utensils & 23 & 127 & 28 & 11 & 0.42 & Moderate \\
\hline 12 & $\begin{array}{l}\text { Know whether HIV is transmitted via touching infected } \\
\text { person }\end{array}$ & 9 & 159 & 14 & 7 & 0.4 & Moderate \\
\hline 13 & $\begin{array}{l}\text { Know whether HIV is transmitted via sharing food with } \\
\text { infected person }\end{array}$ & 16 & 141 & 23 & 10 & 0.39 & Fair \\
\hline 14 & Know the three strategies to prevent HIV infection & 164 & 5 & 14 & 7 & 0.27 & Fair \\
\hline 15 & $\begin{array}{l}\text { Know that HIV can be transmitted to an infant during } \\
\text { pregnancy }\end{array}$ & 109 & 22 & 23 & 36 & 0.22 & Fair \\
\hline 16 & Know whether HIV is transmitted via witchcraft & 6 & 150 & 19 & 14 & 0.17 & Slight \\
\hline \multirow[t]{2}{*}{17} & Know at least two actions to take if they have an STI & 81 & 31 & 44 & 34 & 0.12 & Slight \\
\hline & Mean Values & & & & & 0.43 & \\
\hline
\end{tabular}

Table 5 Kappa Scores for Practice Indicators

\begin{tabular}{|c|c|c|c|c|c|c|c|}
\hline \multirow[t]{2}{*}{ No. } & \multirow[t]{2}{*}{ Indicator } & \multicolumn{2}{|c|}{ Interviewer Agreement } & \multicolumn{2}{|c|}{ Disagreement } & \multirow[t]{2}{*}{ Kappa } & \multirow{2}{*}{$\begin{array}{l}\text { Strength of } \\
\text { Agreement }\end{array}$} \\
\hline & & yes & no & yes \& no & no \& yes & & \\
\hline$\overline{1}$ & Went for 4 ANC visits & 137 & 41 & 3 & 9 & 0.86 & Almost Perfect \\
\hline 2 & Could show an ANC card & 57 & 118 & 7 & 8 & 0.82 & Almost Perfect \\
\hline 3 & Gave birth with a skilled birth attendant & 36 & 142 & 9 & 3 & 0.82 & Almost Perfect \\
\hline 4 & Gave birth in health facility & 38 & 139 & 10 & 3 & 0.81 & Almost Perfect \\
\hline 5 & Have ever used a condom & 59 & 111 & 8 & 12 & 0.77 & Substantial \\
\hline 6 & Received result & 22 & 148 & 10 & 10 & 0.62 & Substantial \\
\hline 7 & Slept under a mosquito net whilst pregnant & 20 & 151 & 13 & 6 & 0.62 & Substantial \\
\hline 8 & Took an HIV test & 16 & 155 & 10 & 9 & 0.57 & Moderate \\
\hline 9 & Received PMTCT counselling & 22 & 141 & 16 & 11 & 0.53 & Moderate \\
\hline 10 & Slept under mosquito net every night whilst pregnant & 31 & 122 & 19 & 18 & 0.5 & Moderate \\
\hline 11 & Received IPT whilst pregnant & 129 & 25 & 16 & 20 & 0.46 & Moderate \\
\hline 12 & Were counselled to take an HIV test & 10 & 160 & 9 & 11 & 0.44 & Moderate \\
\hline \multirow[t]{2}{*}{13} & Own a LLIN & 24 & 125 & 17 & 24 & 0.4 & Moderate \\
\hline & Mean Values & & & & & 0.63 & \\
\hline
\end{tabular}




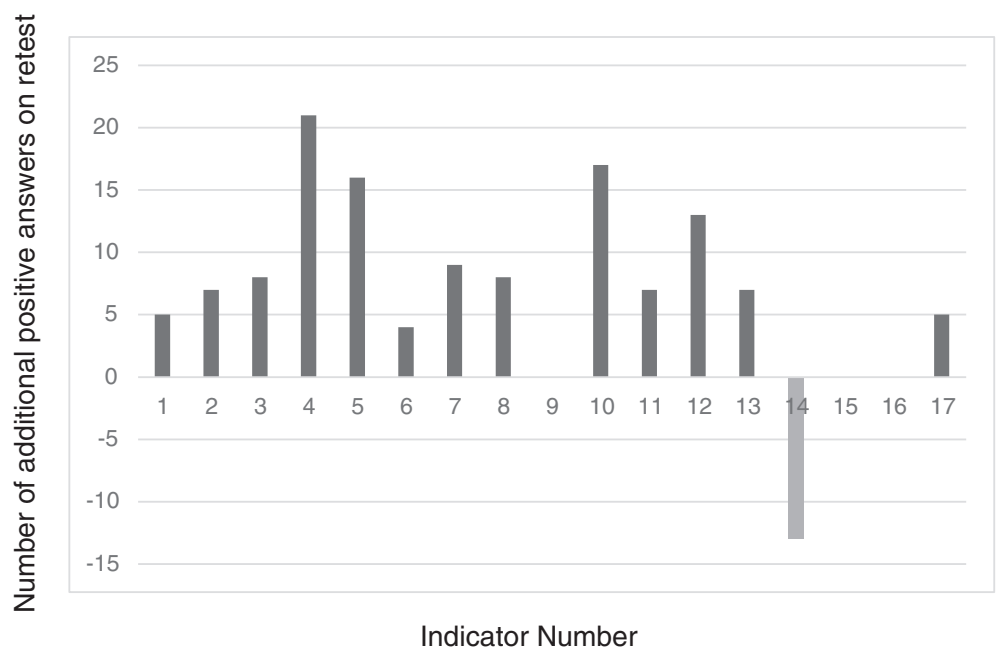

Fig. 1 Additional Positive Answers on the Retest for Knowledge Indicators

retest, and the questionnaire used are freely available as supplementary materials (Additional files 1, 2 and 3).

\section{Discussion}

Our study found substantial agreement for practice indicators and moderate agreement for knowledge indicators. We found evidence of bias for the knowledge indicators but not the practice indicators, as the respondents were more knowledgeable on the retest when interviewed by noninterested data collectors. These findings are strikingly similar to the first LQAS reliability study carried out in 2012 [11].

The average Kappa score for knowledge indicators was $\mathrm{k}=0.43$ in both the first and this current study $(\mathrm{SD}=$ 0.13 and $\mathrm{SD}=0.16$, respectively). There were on average 5.9 (95 \% CI: 4.2 to 7.6 ) more positive answers on the retest for study one, and $6.7(95 \% \mathrm{CI}=3.0$ to 10.4) for the current one. These results support the test-hypothesis that local managers do not collected biased data indicating favourable performance.

For practice indicators the average Kappa score was $\mathrm{k}=$ $0.73(\mathrm{SD}=0.16)$ for the first study, and $\mathrm{k}=0.63(\mathrm{SD}=0.17)$ for the current one. Both Kappa scores indicate 'substantial' agreement between the two data collection teams [19]. There were on average -0.5 (95\% CI: -2.1 to 1 ) more positive answers in the first test, and $-0.2(95 \% \mathrm{CI}$ : -2.9 to 2.5$)$ more positive answers on the second test. These similarities in the findings indicate that the current study results confirm those of the original one.

The current study's design has several important improvements compared to the former one. Firstly, the sample size was larger. In the original reliability study $n=76$ whilst in this study $n=190$. Secondly, in the first study,

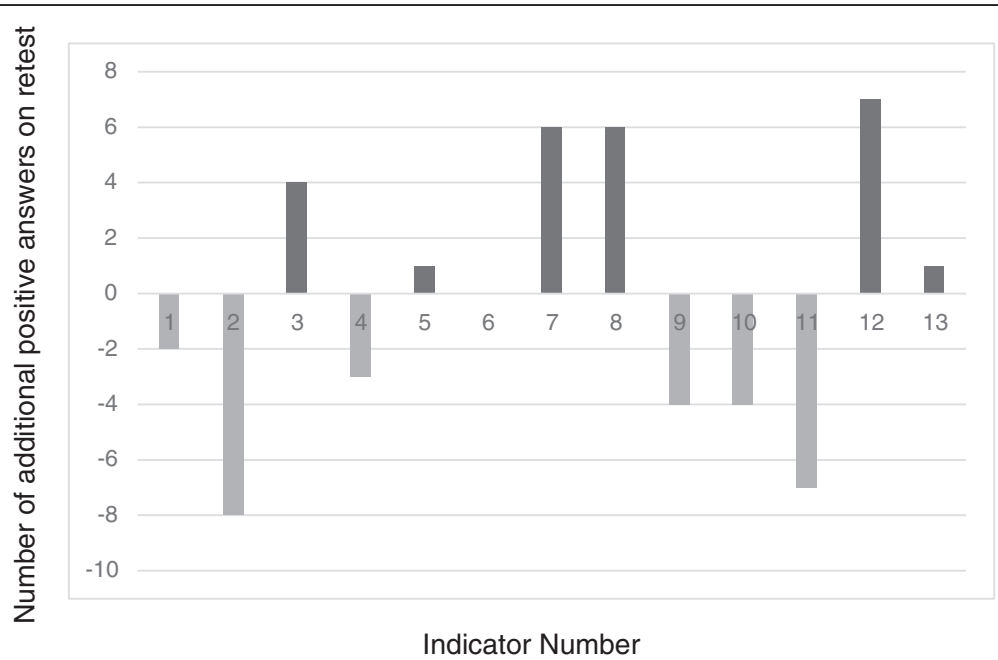

Fig. 2 Additional Positive Answers on the Retest for Practice Indicators 
the data were collected in one district. Hence, there was possibility of contamination of results by the data collectors, despite the authors' efforts to ensure that the data collectors held responsibilities only in the area where they carried out the test and had no responsibilities in areas where they carried out the retest. The contamination is possible since two of the 10 data collectors had responsibilities cutting across the test and retest areas and all the data collectors worked for the same district health authority. In the current study, the test and retest areas were two districts over $200 \mathrm{~km}$ apart. There was therefore virtually no chance that the data collectors could have responsibility for services in both the test and retest areas.

The original reliability study [11] concluded that the evidence of bias revealed on the retest had three possible explanations. Firstly, using interested data collectors could bias findings by making respondents appear less knowledgeable than they actually were (an unlikely possibility); secondly, using non-interested data collectors could bias findings by making respondents more knowledgeable than they actually were (also unlikely); and thirdly, an increase in knowledge in the re-test could be due to a practice effect, which is bias introduced at the retest stage because the respondent has become familiar with the test, or, in this case, the survey questionnaire [22]. The first reliability study concluded that the most likely explanation for the higher knowledge indicators at the re-test was a practice effect.

Only six out of 50 indicators (25 in each district) showed a difference between the test and retest with a $p$ value $\leq 0.05$, and all of these were for knowledge indicators. Of these six knowledge indicators, five showed an increase in knowledge between the test and the retest. Just one indicator out of 50 had respondents more knowledgeable on the test (when interviewed by the interested data collectors) than on the retest with a $p$ value of $\leq 0.05$ (knows that HIV can be transmitted to an infant during pregnancy). Therefore, we think the practice effect is the likely explanation for the higher knowledge indicators found in the current study. Although we classified the indicators using the widely accepted categories ranging from poor to almost perfect agreement given [19], these categories are arbitrary [23]. There are other examples of test-retest research with which we compare our study results. Drum et al. [24] pretested a questionnaire concerning disability access in clinics in North America. Their initial test resulted in a mean Kappa score of 0.61. Whilst they regarded this result as "acceptable", after repeated revisions to the questionnaire and subsequent re-tests they increased the Kappa score to 0.97. However, the authors gave no indication of the sample size and presented no table with results. Flisher et al. [25], however, gave greater detail about their reliability study of a Mental Health Needs Assessment tool. They found very similar results to our survey, with an average Kappa of 0.63 , but they also record considerable variation depending on the indicator (Kappa range: 0.25 to 0.81 ). They concluded that the tool was "relatively reliable". However, the authors had the advantage of reviewing similar test retest studies using the same tool in a variety of settings with which they compared their results.

Whereas our study is comparable to these previous studies, the subjects and research designs were considerably different. We could appraise our results in a more in-depth manner if test re-test data were available for other LQAS or major health surveys used internationally. For example, UNICEF's Multiple Indicator Cluster Surveys, and the Demographic and Health Surveys are large macro surveys of health and demographic variables; yet, there are no reliability studies available for either one. The variability of the Kappa statistics across the indicators in our study suggests that certain types of questions may be more reliable than others. In our current study and in the previous one, the practice indicators appear to be more reliable than knowledge indicators.

Another way to classify the indicators is by the way they are calculated. Some indicators are calculated using simple yes/no questions, while others use more complicated question forms where the data collectors must select multiple responses from a list. The average Kappa score for indicators of the first type is 0.55 , whereas for the second type the result is 0.44 . This suggests that indicators calculated using select multiple questions are less reliable than the indicators calculated using yes/no questions. Further research should be carried out to assess the relative reliability of various question types.

An important limitation of this study is the lack of testretest reliability data available for other major health surveys; therefore, it is difficult for us to define an acceptable level of reliability. The original and current studies are at the vanguard of such studies. Also, this confirmatory study was carried out in two districts with very similar characteristics to the initial study (Pallisa). There is still need to carry out a similar study in a considerably different setting for further comparison. On the retest, a practice effect was observed when examining the knowledge variables, but this is an assumption, which requires further study and confirmation. The carryover effect-the respondents may have remembered the answer they gave in the test and repeated that rather than the recalled the actual variable under study - may also have affected the results of the study, even though a week was given between the test and retest.

\section{Conclusion}

The findings of this study are remarkably similar to those produced in the first reliability study. There is no 
evidence that using local healthcare staff to collect LQAS data biases data collection in an LQAS study. The bias observed in the knowledge indicators was most likely due to a 'practice effect', whereby respondents increased their knowledge as a result of completing the first survey, as no corresponding effect was seen in the practice indicators. Local health managers when well trained in survey methods are capable of collecting reliable information they then use for program management. Perhaps their data are reliable because they use the data and therefore care about its quality.

\section{Additional files}

Additional file 1: 0 to 5 months test. (XLSX $156 \mathrm{~kb}$ )

Additional file 2: 0 to 5 months retest. (XLSX $155 \mathrm{~kb}$ )

Additional file 3: Questionnaire final Copy. (PDF 517 kb)

\section{Acknowledgements}

The study was carried out by the STAR-E project, which is funded by the President's Emergency Plan for AIDS Relief (PEPFAR) through USAID under the cooperative agreement number AID-617-A-00-09-00006 with Management Sciences for Health. The Authors would like to thank Charles Nkolo and John O'Daga for their support during the implementation of this research; and the District Health Officers and health workers of Bukomansimbi and Buikwe districts, Uganda for their commitment and dedication to the health needs of the population they serve.

\section{Funding}

The study was carried out by the STAR-E project, which is funded by the President's Emergency Plan for AIDS Relief (PEPFAR) through USAID under the cooperative agreement number AID-617-A-00-09-00006 with Management Sciences for Health.

\section{Availability of data and materials}

Data supplied as Additional files 1 and 2 in Excel format.

\section{Authors' contributions}

CB was involved in the design, data collection, analysis and drafting the manuscript. RA was involved in the design, data collection, analysis and revising the manuscript. FK was involved in the design, data collection, and revising the manuscript. SL was involved in the design, data collection, and revising the manuscript. JV was involved in the design, analysis and revising the manuscript. All authors read and approved the final manuscript.

\section{Competing interests}

The authors declare that they have no competing interests.

\section{Consent for publication}

Not Applicable.

\section{Ethics approval and consent to participate}

Ethical approval for this research was granted by Makerere School of Public Health, and approval was given by the Uganda National Council of Science and Technology. Written informed consent was obtained for all participants in the study, and the consent form was approved by the ethics committee.

\section{Author details}

'Liverpool School of Tropical Medicine, Pembroke Place, Liverpool L3 5QA, United Kingdom. ${ }^{2}$ Uganda Martyrs University, Nkozi, Uganda. ${ }^{3}$ Uganda Christian University, Mukono, Uganda. ${ }^{4}$ Management Sciences for Health, USAID STAR-E project, Mukono, Uganda.

Received: 18 November 2015 Accepted: 10 August 2016 Published online: 17 August 2016

\section{References}

1. Bryce J, Arnold F, Blanc A, Hancioglu A, Newby H, Requejo J, Wardlaw T, Measurement CWGolC. Measuring coverage in MNCH: new findings, new strategies, and recommendations for action. PLoS Med. 2013;10(5):e1001423.

2. Bchir A, Bhutta Z, Binka F, Black R, Bradshaw D, Garnett G, Hayashi K, Jha P, Peto R, Sawyer C, et al. Better health statistics are possible. Lancet. 2006; 367(9506):190-3.

3. Hedt BL, Pagano M. Health indicators: eliminating bias from convenience sampling estimators. Stat Med. 2011;30(5):560-8.

4. Pagano M, Valadez JJ. Understanding practical lot quality assurance sampling. Int J Epidemiol. 2010;39(1):69-71.

5. Dodge $\mathrm{H}$, Romig $\mathrm{H}$. A method of sampling inspection. Bell System Tech J. 1929:8:(613)613-31.

6. Shewhart WA, Deming WE. Statistical method from the viewpoint of quality control. Washington: The Graduate school, the Department of agriculture; 1939.

7. Robertson SE, Valadez JJ. Global review of health care surveys using lot quality assurance sampling (LQAS), 1984-2004. Soc Sci Med. 2006;63:1648-60.

8. Robertson SE, Anker M, Roisin AJ, Macklai N, Engstrom K, LaForce FM. The lot quality technique: a global review of applications in the assessment of health services and disease surveillance. World Health Stat Q. 1997:50(3-4):199-209.

9. Valadez JJ. Assessing child survival programs in developing countries : testing lot quality assurance sampling. Boston: Dept. of Population and International Health, Harvard School of Public Health; Distributed by Harvard University Press; 1991.

10. Parahoo K. principles, process and issues / Kader Parahoo. 2nd ed. Basingstoke: Macmillan; 2006.

11. Beckworth CA, Davis RH, Faragher B, Valadez JJ. Can health workers reliably assess their own work? A test-retest study of bias among data collectors conducting a Lot Quality Assurance Sampling survey in Uganda. Health Policy Plan. 2015;30(2):181-6.

12. Saal FE, Downey RG, Lahey MA. Rating the Ratings: Assessing the Psychometric Quality of Rating Data. Psychol Bull. 1980;88(2):413-28.

13. Litwin M. How To Measure Survey Reliablity and Validity, vol. 7. London: Sage; 1995

14. Valadez JJ, Weiss W, Leburg C, Davis R. Assessing community health programs : a trainer's guide : using LQAS for baseline surveys and regular monitoring / Joseph J. Valadez ... [et al.]. 2nd ed. St. Albans: TALC (Teaching-Aids at Low Cost); 2007.

15. Petrie A, Sabin C. Medical statistics at a glance. Oxford: Blackwell Science; 2000

16. Sim J, Wright CC. The kappa statistic in reliability studies: use, interpretation, and sample size requirements. Phys Ther. 2005;85(3):257-68.

17. O'Neill TW, Cooper C, Cannata JB, Diaz Lopez JB, Hoszowski K, Johnell O, Lorenc RS, Nilsson B, Raspe $\mathrm{H}$, Stewart O, et al. Reproducibility of a questionnaire on risk factors for osteoporosis in a multicentre prevalence survey: the European Vertebral Osteoporosis Study. Int J Epidemiol. 1994:23(3):559-65.

18. Brown WJ, Trost SG, Bauman A, Mummery K, Owen N. Test-retest reliability of four physical activity measures used in population surveys. J Sci Med Sport. 2004;7(2):205-15.

19. Landis JR, Koch GG. The measurement of observer agreement for categorical data. Biometrics. 1977;33(1):159-74

20. Uebersax JS. Diversity of decision-making models and the measurement of interrater agreement. Psychol Bull. 1987;101(1):140-6.

21. Choi BC, Noseworthy AL. Classification, direction, and prevention of bias in epidemiologic research. J Occup Med. 1992;34(3):265-71.

22. Bird CM, Papadopoulou K, Ricciardelli P, Rossor MN, Cipolotti L. Test-retest reliability, practice effects and reliable change indices for the recognition memory test. Br J Clin Psychol. 2003;42(4):407-25.

23. Brennan P, Silman A. Statistical Methods For Assessing Observer Variability In Clinical Measures. In: British Medical Association. 1992. p. 1491.

24. Drum CE, Horner-Johnson W, Walsh ES. Construction and validation of the Outpatient Health Care Usability Profile (OHCUP). Disabil Health J. 2012;5(4):292-7.

25. Flisher A, Sorsdahl K, Joska J. Reliability of the Camberwell Assessment of Need for South African mental health service users. Int I Soc Psychiatry. 2012:58(1):47-54 